\title{
Simultaneous Recordings of Visual Cortex and Superior Colliculus Field Potentials in the Rabbit
}

\author{
STEPHANE MOLOTCHNIKOFF, MICHEL DUBUC AND JEAN REAL BRUNETTE
}

SUMMARY: The field potentials recorded simultaneously at various depth of the rabbit's visual cortex and superior colliculus were analysed following light $O N$ and light OFF. The collicular $O N$ and $O F F$ potentials exhibited three slow components superimposed by fast rhythmic oscillations. Only the first slow component reversed its polarity with penetration from surface negative to

RÉSUMÉ: Les potentiels évoqués parle déclenchement (ON) et la cessation (OFF) d'un stimulus lumineux furent comparés au niveau du cortex visuel (CV) et du collicule supérieur (CS), au cours de leur pénétration, chez le lapin. Contrairement aux potentiels $O N$ et OFF cornéens qui présentent une morphologie et une sensibilité très différentes, les réponses $O N$ et $O F F d u$ $C S$ et du CV paraissent plus comparables. L'amplitude de la réponse OFF bien que souvent légèrement plus faible positive in depth. The cortical $O N$ and OFF responses similarly contained three slow waves which all reversed their polarity with electrode penetration: from surface positive to negative in deeper layers. The most striking difference between $O N$ and OFF cortical responses is the absence of fast rhythmic oscillations in the cortical ON response.

peut atteindre l'amplitude de la réponse ON. Morphologiquement, les réponses ON et OFF tant au niveau cortical que colliculaire contiennent trois composantes lentes de polarité inverse: positivité de surface au CV et négativité de surface au CS. En outre, la réponse ON corticale se différencie par l'absence d'activité rythmique de type oscillatoire laquelle est présente aux niveaux du OFF cortical et du ON et OFF colliculaires.
From the Visual Physiology Laboratory of the Department of Ophthalmology, MaisonneuveRosemont Hospital, Université de Montréal. Dr. Molotchnikoff is from the Biology department, Université de Montréal and Michel Dubuc was supported by training grant No. 217-617-489 of the Ministère de l'Education du Québec.

Reprint requests: Docteur Stéphane Molotchnikoff, Laboratoire de Physiologie Visuelle - J-1, 5689, Boul. Rosemont, Montréal, Canada H1T 2 H1.

\section{INTRODUCTION}

The electrophysiological relationships of the superior colliculus and the visual cortex have been substantially documented in recent years. These have been studied in rats (Goodale, 1973; Creel et al, 1973) cats (Altman and Malis, 1962; Tamai and Ogawa, 1972) and Teleost fishes (Vanegas et al, 1971). Most studies relied on electrical stimulation of the optic nerve (Sterling et al, 1968), or short light pulses (Altman and Malis, 1962).

Responses to cessation of light have received much less attention. In the corneal electroretinogram, the response to cessation of light i.e. the Off response is represented in mammals by a simple negative deflection: the " $d$ " wave, while the ON effect i.e. the classical ERG is much better known. In contrast, micro-electrode studies at the retinal level have shown that the OFFcenter units are about as numerous as ON-center units.

This study describes field potentials evoked both by brightening step change of light (light $\mathrm{ON}$ ) and cessation (light OFF) of stimulus, recorded simultaneously during superior colliculus (C.S.) and visual cortex (C.V.) penetration in the rabbit. Particular attention was directed to the differentiation of the fast rhythmic oscillations from the slow components. It is shown that the $\mathrm{ON}$ and $O F F$ responses are quite different in some aspects. Thus, at the cortical level the $\mathrm{ON}$ responses do not contain fast rhythmic oscillations while they are present in the OFF response. At collicular level both responses, ON and OFF, contain fast rhythmic oscillations. 


\section{MATERIAL AND METHODS}

Animal Preparation

The experiments were performed on albino rabbits of 2 to $3 \mathrm{~kg}$. anesthetized by intravenous injections of nembutal, $24 \mathrm{mg} / \mathrm{kg}$. Surgical and pressure sites were infiltrated with $2 \%$ Xylocaine. Curarisation was initiated by injecting $40 \mathrm{mg} / \mathrm{kg}$. of Gallamine Triethiodide and maintained by hourly administration of 20 $\mathrm{mg} / \mathrm{kg}$. doses. The animal's head was clamped in the stereotaxic apparatus and the craniotomies extended from Sawyer (1954) coordinates, $3 \mathrm{~mm}$ posterior to the lambdoid point, and laterally to $7 \mathrm{~mm}$. The cortex was covered with mineral oil and Agar gel.

\section{LIGHT STIMULATION}

Light stimulation was provided by two coiled Tungsten filament bulbs powered by 100 volts stabilised DC. Projecting lenses focused the two beams on the cornea.

Intensity was evaluated at corneal level to be 3.25 lumen second/square foot for 100 integrated flashes of 100 milliseconds duration. Apertures, intensities and durations of the two beams could be controlled independently.

\section{TRIGGER AND RECORDING SYSTEM}

A quartz crystal clock (Digitimer) triggered the shutters and recording devices. Cortical and collicular evoked potentials were recorded monopolarly and simultaneously through steel electrodes $100 \mu$ in diameter insulated down to the tip. Impedance of these electrodes measured at $1 \mathrm{KHz}$. averaged 10,000 ohms. They were positioned stereotaxically. For the superior colliculus, coordinates were $P$ : 9-10 $\mathrm{mm}$. and $\mathrm{L}: 2-3 \mathrm{~mm}$. Many positions were evaluated for the visual cortex; all were in Area I (Thompson et al, 1950). Since no significant differences were observed, visual cortex coordinates commonly chosen were $P$ : 14 and $L: 3-5 \mathrm{~mm}$.; which are Area I, close to the splenial sulcus.

Depth of penetration depended on protocol and will be indicated in the text.
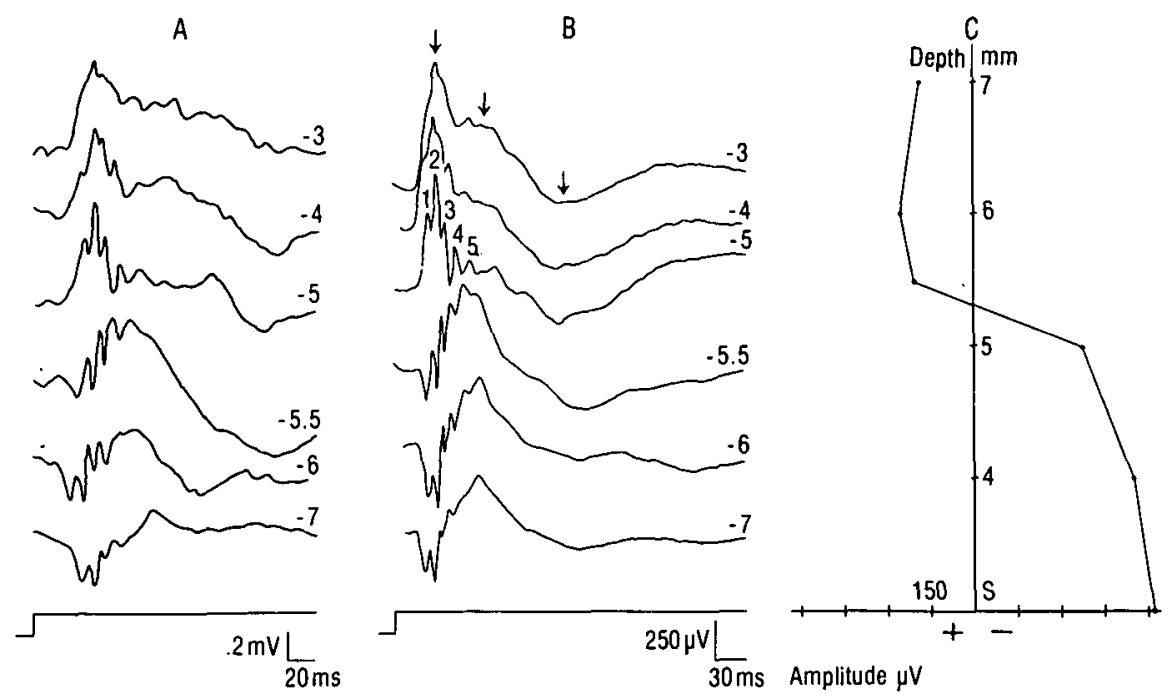

Figure I - Field potentials recorded at the superior colliculus (S.C.) following light $\mathrm{ON}$. A: unaveraged response, B: averaged response, $\mathrm{C}$ : amplitude profile during the penetration of the S.C. of the first, slow, component. Note at the surface three slow components culminating at 45-50, 100, $180 \mathrm{msec}$. respectively. Positivity downward. Numbers on the right in A and B tracings indicate the depth from cortical surface.

Responses were amplified on Tektronix No. 122 amplifiers with passbands selected from .8 to $250 \mathrm{~Hz}$. displayed on Tektronix 564 oscilloscope and photographed for subsequent analysis. Averaging was done on line with a computer of average transients (C.A.T.). All averaged responses illustrating the text are averages of 50 with an analysis time of $500 \mathrm{msec}$ post stimulus onset.

At the end of the experiments, electrode tip positions were marked by electrolytic lesions by feeding 50

A current for 20 seconds in the recording electrodes. Histologic preparations were obtained and stained with cresyl violet for microscopic observation. (Fig. 6)

\section{RESULTS}

\section{A) SUPERIOR COLLICULUS FIELD POTENTIALS}

\section{1) Light ON responses.}

It is known that evoked potentials of primary sensory areas are variable from one animal to another as well as between investigators. These discrepancies are due to sensitivity of evoked cortical responses to anesthesia, stimulating parameters, and variations in sites of recording. In order to avoid any confusion with previous descriptions, we shall refrain from any formal systematisation. Responses will be characterised by surface polarity and peak time.

At the surface of the superior colliculus (penetration: $-3.0 \mathrm{~mm}$. under cortical surface) light $\mathrm{ON}$ field potentials began with a $30-35 \mathrm{msec}$ latency, negative-going, deflection. (Fig. 1A-B). The smooth contoured response showed three major slow components with respective peak times of 45-50, 100 and $180 \mathrm{msec}$ indicated by arrows in all figures. The first two were negative and the last positive (Fig. 1).

Progressive penetration gradually modified the configuration of the responses. One striking difference with penetration was the advent of superimposed fast rhythmic oscillations of $75-80 \mathrm{c} / \mathrm{s}$. Five of these can be seen in Figure 1B at depth -5.0 $\mathrm{mm}$. Their number varied from experiment to experiment but were never more than five. Further penetration produced polarity reversal of the first slow component peaking at $45-50$ msec: this component would be defined as the primary response because it is of shortest latency. The second slow potential remained negative throughout penetration, 

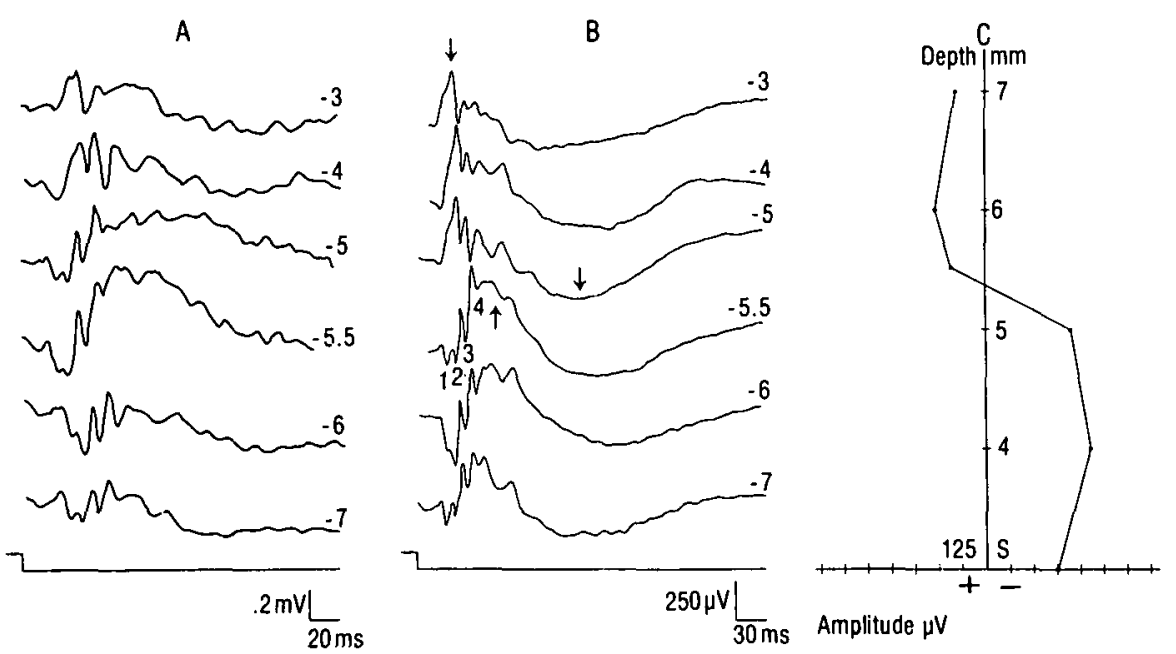

Figure 2 - Field potentials recorded at the superior colliculus (S.C.) following light OFF. A: unaveraged response, $\mathrm{B}$ : averaged response, $\mathrm{C}$ : amplitude profile during collicular penetration. Positivity downward. Numbers on the right in $A$ and $B$ tracings indicate the depth from cortical surface.

whereas the last component decreased in amplitude with depth and seemed to disappear below -5.5 . $\mathrm{mm}$. As illustrated in Figure $1 \mathrm{C}$ the polarity reversal of the slow, short latency, component occurred at approximately $5.3 \mathrm{~mm}$. below collicular surface.

This reversal, along an axis of penetration perpendicular to the surface suggests that the primary response was generated by elongated and radially oriented cellular elements. In fact, the electrolytic markers showed that the potential reversed when the tip of the electrode was located in the stratum griseum which is the most superficial layer containing radially arranged cellular elements. (Fig. 6)

\section{2) Light OFF responses}

Figure 2 illustrates the light OFF field potentials obtained after one second of illumination and recorded at the same site and with the same electrode as the ON responses described previously (Fig. 1). Slight similarities were observed. The latency of the initial, surface, negative, deflection was $35 \mathrm{msec}$, and the level of polarity reversal during penetration was identical for both responses.

The major differences in the configuration of $\mathrm{ON}$ and $\mathrm{OFF}$ collicular

responses reside in their amplitude and the number of fast rhythmic oscillations. Thus, the first slow component was of smaller amplitude in OFF responses; compare Figures $1 \mathrm{C}$ and $2 \mathrm{C}$. The second and third slow components peaking at 100 and $180 \mathrm{msec}$ respectively were of simi-
A

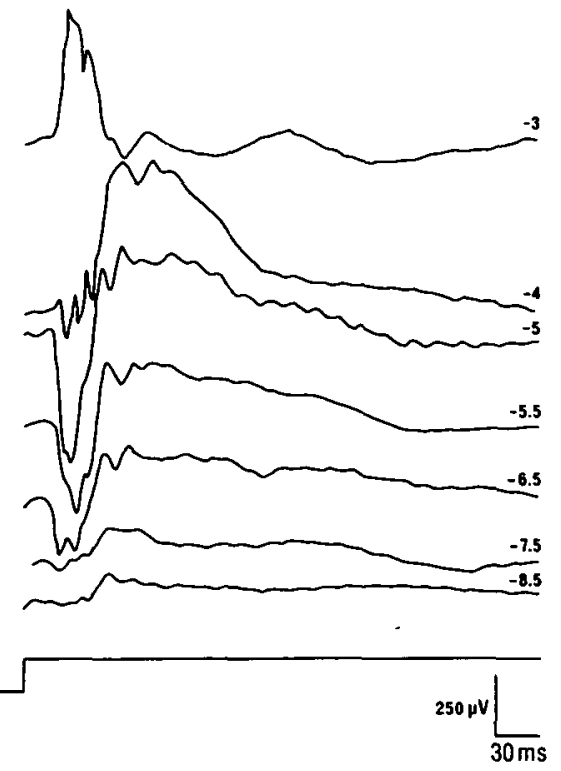

Figure 3 - Field potentials recorded at the superior colliculus (S.C.) following light ON: $A$ and light OFF: B. Note the higher number and amplitude of the rhythmic oscillations in the OFF response. In all experiments the OFF response contained more or at least the same number of oscillations as the ON response. Numbers indicate the depth from the cortical surface. Positivity downward.

lar amplitude except for the third component which was greater in OFF responses at deep recordings. At $-6.00 \mathrm{~mm}$. it is still prominent while barely present in $O N$ responses: Figures $1 \mathrm{~B}$ and $2 \mathrm{~B}$.

Figure 3 illustrates the one major characteristic which differentiates ON and OFF responses, and which has been consistently recorded. The fast oscillatory components, although of identical frequency (70-80 $\mathrm{c} / \mathrm{s}$ ) were commonly of much greater amplitude and more numerous in OFF than in ON responses.

This is shown in Figure 3 drawn from another experiment. Recordings taken from -4 to $-5 \mathrm{~mm}$. depths, approximate isopotential line, show this difference (Fig. 3A, 3B). The OFF response can obtain up to 7 or 8 rhythmic oscillations while in the ON responses 6 oscillations were never recorded. Both increments and decrements of illumination produce, at collicular levels, rhythmic oscillations which are greater with stimulus dimming, suggesting that this mode of stimulation has less damping effects on the cellular network producing them. 



Figure 4-Field potentials recorded at the visual cortex (AREA 1) following light ON. A: unaveraged response, $B$ : averaged response, $C$ : amplitude profile during penetration. Note the smoothness of this response: no oscillations were seen. $S$ Surface. Numbers on the right of the tracings in A and B indicate the depth. Positivity downward.

\section{B) VISUAL CORTEX FIELD POTENTIALS}

\section{I) Light $O N$ responses.}

Figure $4 \mathrm{~A}, \mathrm{~B}, \mathrm{C}$, illustrates the ON responses evoked at visual cortical levels. These were recorded through a second channel in parallel and simultaneously with the collicular responses. The epicortical $\mathrm{ON}$ response was a positive deflection of 30 to $35 \mathrm{msec}$ latency whereas at collicular surface the $O N$ response was negative. (Fig. 1) The cortical ON field potentials exhibited three slow waves peaking at 45,95 and 180 msec (arrows). The first two were positive while the last one was negative. All three components reversed polarity within $1.5 \mathrm{~mm}$. below the cortical surface. Similar to the collicular responses, the mechanisms that generated the field potentials must be such that a dipole is established for each wave between the superficial and deeper cortical layers. Also, the dipole is only established from activated neural elements which are elongated, and oriented in parallel to the electrode penetration. Furthermore, it is necessary that the current flow be initiated from a focal point, that is from a circumscribed portion of the neural segment, and thus forms a driving, extra-cellular, current, dipole.

The behavior of the first slow potential, the primary response, during cortical penetration, is shown in Fig. 4C. As illustrated, its reversal occurred within $1 \mathrm{~mm}$. of the cortical surface and reached maximum amplitude $.5 \mathrm{~mm}$. deeper at $1.5 \mathrm{~mm}$. under the surface. The broader, slow component, which peaked at $180 \mathrm{msec}$ reversed its polarity. This was not the case of the third slow collicular component which also peaked at $180 \mathrm{msec}$. At the colliculus it was higher superficially and decreased with penetration. Fig. 1B.

Another notable difference between collicular and cortical $O N$ field potentials was the smoothness of the cortical response. Only deep in the cortex, probably in the white matter, were fast oscillatory potentials present. In contrast, at the collicular level these were present from the onset in light $\mathrm{ON}$ responses. Fig. 1.

\section{2) Light OFF responses.}

As in the colliculus the OFF responses were recorded with the same electrode and at the same sites as $\mathrm{ON}$ cortical responses. Again three major slow components were recorded peaking respectively at 50 , 80-100 and $180 \mathrm{msec}$ Fig. 5A, B. They all reversed polarity at the same depth as ON cortical responses and their amplitudes were comparable. (Fig. 4 and 5) Similar to the collicular OFF, the last slow component ( $180 \mathrm{msec}$ peak time) gained amplitude with depth of penetration.

The most striking difference between $\mathrm{ON}$ and OFF cortical re-
Figure 5 - Field potentials recorded at the visual cortex following light OFF. (AREA 1) A: unaveraged response, $B$ : averaged response, $C$ : amplitude profile during penetration. Note the presence of fast rhythmic oscillations. S: Surface. Numbers on the right of tracings $A$ and $B$ indicate the depth. Positivity downward.
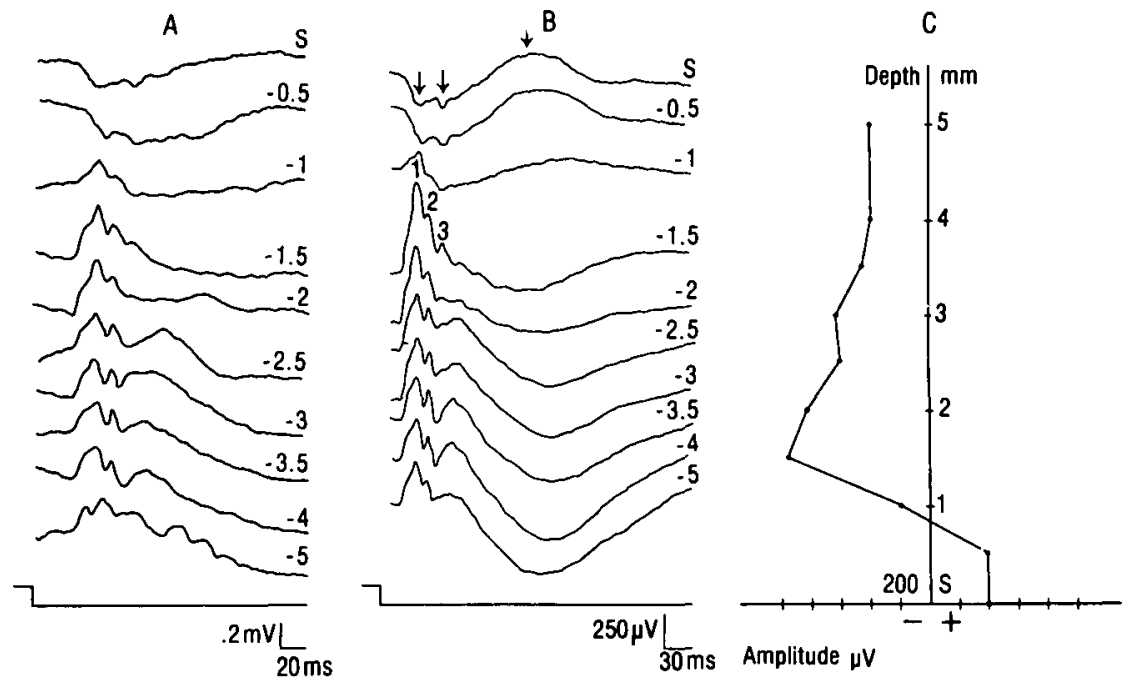
sponses was the presence of fast superimposed oscillations of about $70-80 \mathrm{c} / \mathrm{s}$. These oscillations became prominent following the polarity reversal. Two to three such oscillations were generally encountered. At depth -1.5 in Figure 5B three fast rhythmic oscillations were prominent on the slow component.

\section{DISCUSSION}

Data presently described at collicular levels are similar to those presented in previous investigations. Thus, at the surface of the superior colliculus, the field potentials evoked by short pulses of light and by electrical stimulation of the optic nerve were negative deflections in rats (Goodale, 1973) cats and rabbits (Bishop and O'Leary, 1942) and teleosts (Vanegas et al, 1971). From all of these species the authors obtained a reversal of responses and isoelectric lines located in the superficial layers of the tectum. At the cortical surface the variability of the evoked response is well established (Steriade, 1969). However, in nembutal anesthetized cats an initial positive deflection is always recorded. Since the primary responses are inverted at the surfaces of the colliculus and cortex respectively, the source of the dipole produced by cellular activation lies deep in the colliculus while it is superficial in the cortex.

Consequently, in the superior colliculus the optic tract fibers make synaptic contact on the apical part of the dentritic tree, remote from the cell body, whereas in the visual cortex the optic radiations contact cortical cells more directly i.e. close to the cell body.

Histological observations have shown in the superficial layers of the superior colliculus, a majority of neurons are elongated in shape with ovoid perykarion and a large dentritic tree extending towards the surface (Szekely, 1973; Buser, 1956). On the other hand it has been shown that the optic radiation fibers, which represent the specific afferents, tend to terminate predominantly in cortical layer III and IV, V, where the large pyramidal cell bodies are mostly seen (Szentagothai and Kuhnt, 1973; Rose, 1964).

The results shown can be summarized in the following way: at both structures the light " $\mathrm{ON}$ " and "OFF" evokes three slow components peaking respectively at $40-50$, 80-100, 180-200 msec. Superimposed upon those waves, fast rhythmic oscillations are recorded in all responses except cortical ON responses which do not exhibit any fast activity. Comparing the $O N$ and
OFF evoked responses the following similarities and differences have been observed. Both responses had the same latency at both structures. While the response to cessation of light is barely perceptible in the corneal electroretinogram it is quite evident at the superior colliculus and visual cortex, and in some instances can be equal in amplitude to the ON response. Both responses last up to $200 \mathrm{msec}$, thus pulsations of light of less than 200 msec duration may not

Figure 6- Electrolytic lesion indicating the position of the tip of the electrode. Due to the high magnification (X25) only a portion of the superior colliculus can be seen. There are numerous large cell bodies extending to the left of the central part of the lesion. In this experiment the lesion was made when the tip of the electrode recorded the maximal positivity of the collicular $\mathrm{ON}$ response.

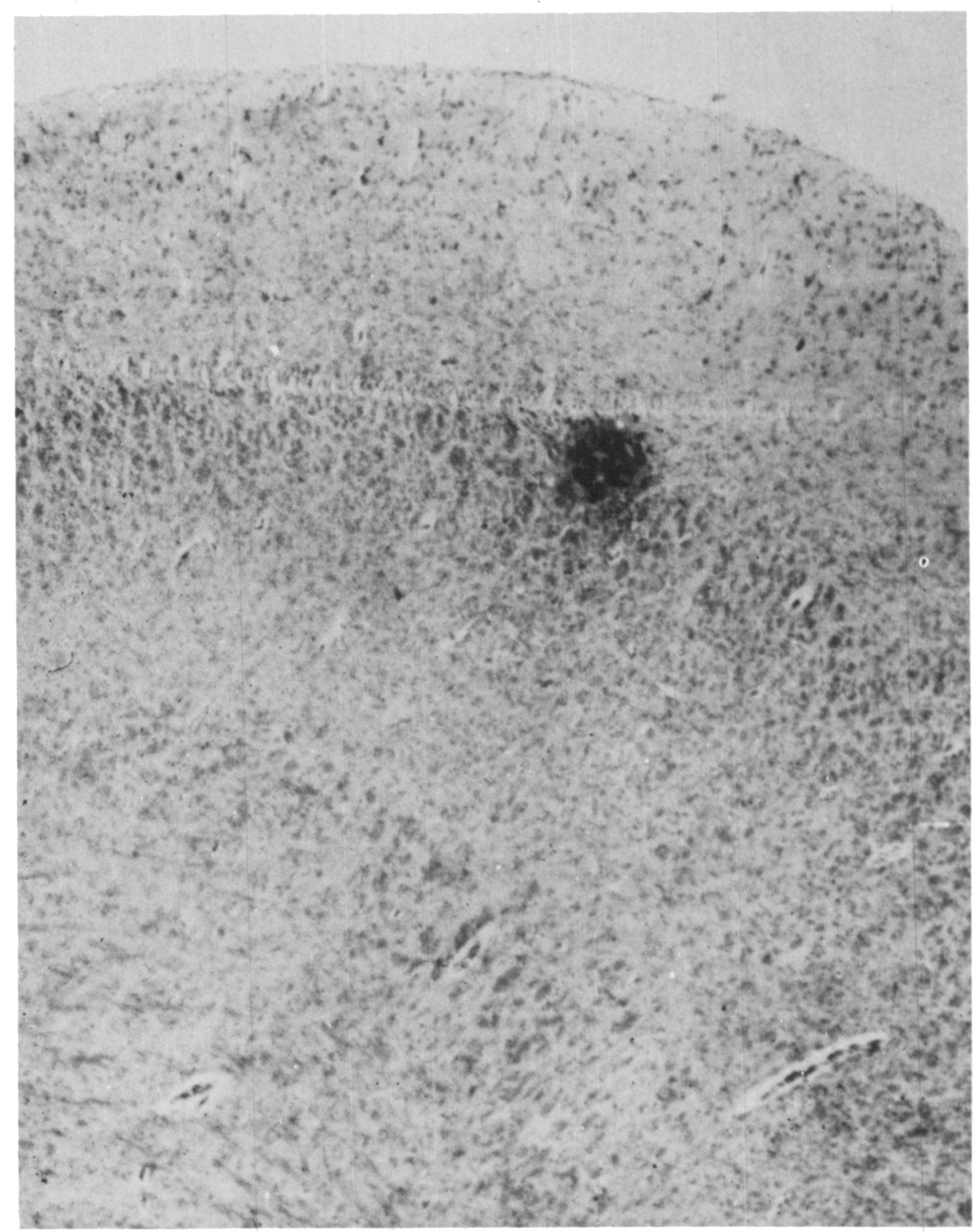


reveal completely an OFF response.

However, the first slow component reverses its polarity at both structures and from two types of stimuli. Because of its short latency it is probably the response to the excitation of specific afferents. In contrast, the second and third slow components appear to reverse polarity only at the cortical level.

This suggests that the synaptic activation which produces these waves is more spatially restricted in the cortex than in the superior colliculus. In the latter a large spread of the synaptic contacts which produces the second and third wave would not permit a potential reversal. The second, post primary, slow component could be due to either excitation from slow conducting fibers, or internuncial neuron activity, or both. The third slow component could be the result of neuron activity in response to non specific afferents.

The last difference between $O N$ and OFF responses, worthy of being discussed, is the absence of oscillatory activity in the ON cortical response. Previous studies (Kozak, 1971; Steinberg, 1966; Dill, 1968; Steriade, 1969; Molotchnikoff, 1970) have shown that oscillatory potentials were present in the optic nerve, as well as in the lateral geniculate body. Specifically, Kozak (1971) showed in the cat that prominent rhythmic activity can be recorded from the lateral geniculate body at both light $\mathrm{ON}$ and OFF. It is thus unlikely that the fast rhythmic oscillations only in the OFF cortical response are a manifestation of optic fiber activity. It suggests that the absence of oscillatory potential in the ON cortical response is due to an intra-cortical network. In primates, the oscillatory potentials are limited to area 17 (Creutzfeld and Kuhnt, 1973). In both the superior colliculus and visual cortex the rhythmic oscillations are sensitive to barbiturate when they are evoked by electrical stimulation of the optic nerve (Steriade, 1969; Tamai and Ogawa, 1972). They have concluded that they are post-synaptic in origin, and produced by repetitive discharge of internuncial neurons.

One possible explanation of the absence of cyclical activity in the ON cortical response could be the reduction of retinal output upon illumination. Granit (1955) showed that the dark adapation increases the rate of the spontaneous activity in some units of the optic nerve. Arduini and Pinneo (1962, in Steriade, 1969) also showed that the tonic activity of the optic nerve fibers, during illumination, never reaches the level of activity during darkness. Thus, in some fibers it seems that darkness increases the firing rate. This could act on cortical neurons by increasing their reverberating activity which would be reflected by fast oscillatory potentials in the OFF cortical response. It seems that these recurrent loops are more powerful in the superior colliculus than in the visual cortex and more sensitive to cessation of illumination.

\section{ACKNOWLEDGEMENTS}

The authors wish to thank Mrs. D. Harvey for secretarial work, Mrs. P. Plante for technical assistance in histological preparation and the department of Medical Photography of the Maisonneuve-Rosemont Hospital.

\section{REFERENCES}

ALTMAN, J., MALIS, L. I.: An Electrophysiological Study of the Superior Colliculus and Visual Cortex. Experimental Neurology, 5, 233-249, 1962.

BUSER, P.: Etude de l'Activité Electrique du Lobe Optique des Vertébrés Inférieurs. Journal of Physiology, 48, 49-71, 1956.

CREEL, D. J., DUSTMAN, R. E. BECK, E. C.: Visually Evoked Responses in the Rat, Guinea Pig, Cat, Monkey, and Man. Experimental Neurology, Vol. 40, No. 2, 351-366, 1973.

CREUTZFELDT, D. D., KUHNT, U.: Visual Central Processing of Information A and B. In Handbook of Sensory Physiology, Vol. 7-3, 1973.
GOODALE, M. A.: Cortico-Tectal and Intertectal Modulation of Visual Responses in the Rat's Superior Colliculus. Experimental Brain Research, 17, 75-86, 1973.

GRANIT, R.: Receptors and Sensory Perception. Yale University Press, New Haven, 1955.

KOZAK, W. M.: Electroretinogram and Spike Activity in Mammalian Retina. Vision Research, Suppl. No. 3, 129-149, 1971.

MOLOTCHNIKOFF, S.: Etude de la Morphologie de l'E.R.G. et des Potentiels Evoqués du Nerf Optique du Lapin Albinos en Fonction de la Duplicité Rétinienne. Thèse de Maitrise, Université de Montréal, 1970.

ROSE, J. E.: I. Retrograde Changes in the DLGB after Destruction of Cells in Various Layers of the Striate Region. Journal of Comparative Neurology, 125, 95-120, 1964.

II. Cytoarchitectonic Structure of the Striate Region and DLGB; Organization of Geniculo Striate Projections. Journal of Comparative Neurology, 125, 121-140, 1964.

SAWYER, C. H., EVERETT, J. W., GREEN, J. D.: The Rabbit Diencephalon in Stereotaxic Coordinates. Journal of Comparative Neurology, 101, 801-824, 1954.

STEINBERG, R. H.: Oscillatory Activity in Optic Tract of Cat and Light Adaptation. Journal of Neurophysiology, 29, 149-156, 1966.

STERIADE, M.: Physiologie des Voies et des Centres Visuels. Edition Masson, Paris, 1969.

STERLING, G., PICKERING and FREEMAN, $W$. J.: Superior Colliculus Evoked Response on Anesthetized Cats: Space, Time Characteristics. American Journal of Physiology, 21, 152-157, 1968.

SZEKELY, G.: Anatomy and Synaptology of the Optic Tectum. Handbook of Sensory Physiology. Edition R. Jung, SpringerVerlag, 7-3, 1973.

TAMAI, M., OGAWA, T.; Interaction between Cortico-Tectal and Retino-Tectal Inputs as Revealed by Analysis of Field Potentials of the Cat's Superior Colliculus. Tohoku Journal of Experimental Medicine, 107, 127-142, 1972.

THOMPSON, J. M., WOOLSEY, C. N., TALBOT, S. A.: Visual Areas I and $I 1$ of Cerebral Cortex of Rabbit. Journal of Neurophysiology, 13, 277-288, 1950.

VANEGAS, H., ESSAYAG-MILLAN, E., LAUFER, M.: Response of the Optic Tectum to Stimulation of the Optic Nerve in the Teleost Eugerres Plumieri. Brain Research, 31, 107-118, 1971. 